\title{
ON or OFF?: Modulating the N-Methyl-D-Aspartate Receptor in Major Depression
}

\author{
Shi Yu Chan ${ }^{1}$, Edward Matthews ${ }^{2}$ and Philip W. J. Burnet ${ }^{1 *}$ \\ ${ }^{1}$ Department of Psychiatry, Warneford Hospital, University of Oxford, Oxford, UK, ${ }^{2}$ Green Templeton College, University of \\ Oxford, Oxford, UK
}

Since the discovery that a single dose of ketamine, an N-methyl-D-aspartate receptor (NMDAR) antagonist, had rapid and long-lasting antidepressant effects, there has been increased interest in using NMDAR modulators in the pharmacotherapy of depression. Ketamine's efficacy seems to imply that depression is a disorder of NMDAR hyperfunctionality. However, studies showing that not all NMDAR antagonists are able to act as antidepressants challenge this notion. Furthermore, NMDAR co-agonists have also been gaining attention as possible treatments. Co-agonists such as D-serine and sarcosine have shown efficacy in both pre-clinical models and human trials. This raises the question of how both NMDAR antagonists and agonists are able to have converging behavioral effects. Here we critically review the evidence and proposed therapeutic mechanisms for both NMDAR antagonists and agonists, and collate several theories on how both activation and inhibition of NMDARs appear to have antidepressant effects.

\section{OPEN ACCESS}

Edited by:

Kimberly Raab-Graham, Wake Forest School of Medicine,

USA

Reviewed by:

Hansen Wang,

University of Toronto, Canada Mohiuddin Ahmad, University of Oklahoma Health

Sciences Center, USA

*Correspondence:

Philip W. J. Burnet phil.burnet@psych.ox.ac.uk

Received: 04 November 2016 Accepted: 27 December 2016 Published: 13 January 2017

Citation:

Chan SY, Matthews E and Burnet PWJ (2017) ON or OFF?: Modulating the N-Methyl-D-Aspartate Receptor in Major Depression.

Front. Mol. Neurosci. 9:169. doi: 10.3389/fnmol.2016.00169
Keywords: NMDAR antagonist, glycine site, mTOR, depression, subunit

\section{INTRODUCTION}

The N-methyl-D-aspartate receptors (NMDARs) are a class of ionotropic glutamate receptors that are widely expressed in the brain. They are composed of two glycine-binding GluN1 subunits and two glutamate-binding GluN2 subunits (GluN2A, GluN2B, GluN2C and GluN2D). In the adult brain, the majority of NMDARs are a combination of GluN1 with GluN2A and/or GluN2B (Papadia and Hardingham, 2007), that play important roles in neurodevelopment, synaptic plasticity, learning and memory (Morris et al., 1986; Riedel et al., 2003; Hunt and Castillo, 2012; Burnashev and Szepetowski, 2015). Conversely, dysregulation of NMDARs is associated with some neuropsychiatric disorders, such as schizophrenia, where NMDAR hypofunction has been evinced through the psychotomimetic effects of NMDAR antagonists (Olney et al., 1999), and NMDAR hyperfunction has been associated with excitotoxicity and neurodegeneration (Zhou et al., 2013). This has led to the inverted-U curve hypothesis of NMDAR function (Lipton and Nakanishi, 1999), and highlighted NMDAR modulators as potential therapeutic interventions for neuropsychiatric disorders.

The NMDAR co-agonists, D-serine, D-alanine and glycine, and glycine uptake inhibitors, have proved effective at ameliorating negative symptoms of schizophrenia when used as adjunctive therapies (Heresco-Levy et al., 2004, 2005; Tsai et al., 2004, 2006; Kantrowitz et al., 2010), and support the NMDAR hypofunction theory for this disorder. The NMDAR antagonist, memantine, has proved to be therapeutically beneficial in some cases of Alzheimer's disease (Reisberg et al., 2003), where glutamate-mediated neuropathology is posited. However, 
recent attention has focused on the NMDAR as a therapeutic target for major depression, and despite often ambiguous mechanistic insight, both inhibition and stimulation of this receptor convey antidepressant properties. This review article will critically evaluate the current literature reporting the validity of NMDAR modulation in major depression, and will propose a mechanism by which the function of this receptor in an "on" or "off" state may have antidepressant actions.

\section{NMDAR MODULATION AS A THERAPEUTIC STRATEGY: CONFLICTING EVIDENCE}

Interest in the utility of NMDAR modulators in depression developed when a single sub-anesthetic dose of ketamine, a non-competitive NMDAR antagonist, was shown to produce rapid and long-lasting antidepressant effects (Berman et al., 2000). However, while much headway has been made in elucidating the mechanisms behind ketamine's efficacy, our understanding of the role of NMDARs in mood disorders is far from complete. Added to this is the complexity of the different sub-environments of different brain regions, different types of neurons (i.e., pyramidal neurons and interneurons) and the diversity of NMDAR subunits and regulators. Given the volume of information obtained from research on ketamine, it appears that NMDAR antagonists have great potential as a new class of antidepressants. This is supported by studies on other NMDAR antagonists, such as nitrous oxide (Zorumski et al., 2015) and lanicemine (Sanacora et al., 2014; Downey et al., 2016), which show great promise as potential antidepressants in pre-clinical models. However, memantine does not display antidepressant properties (Zarate et al., 2006), and numerous NMDAR agonists, in particular agonists of the glycine site (e.g., GLYX-13, Moskal et al., 2014), may be potential treatments for depression. This raises the question of how both NMDAR antagonists and agonists are able to have antidepressant effects (Figure 1).

\section{NMDAR ANTAGONISTS: THE MECHANISM OF KETAMINE}

Ketamine is an anesthetic and a psychotomimetic drug (Krystal et al., 1994) with antidepressant properties (Berman et al., 2000). Recently, Miller et al. (2016) reviewed the evidence behind two dominant hypotheses explaining ketamine's mode of action-direct inhibition, and disinhibition (Figure 1). The "disinhibition" theory proposes that ketamine antagonizes NMDARs on inhibitory interneurons, therefore removing the inhibition of pyramidal neurons, and increasing glutamate neurotransmission. The "direct inhibition" theory, however, proposes that NMDARs are tonically activated by ambient glutamate and glutamate from spontaneous-releasing synaptic vesicles, and that this detrimental tonic activation is directly inhibited by ketamine.
Although a consensus has not been reached for the initiation of ketamine's activity, research has highlighted certain key elements that may provide a clue for how NMDAR antagonists work as antidepressants. Research has shown that ketamine blockade of NMDARs inhibits the eukaryotic elongation factor 2 (eEF2) kinase, which leads to eEF2 de-phosphorylation and de-suppression of Brain-Derived-Neurotrophic-Factor (BDNF) translation (Autry et al., 2011). The levels of BDNF and its receptor, Tropomyosin receptor kinase B (TrkB), have been positively correlated with antidepressant efficacy, possibly through their roles in synaptogenesis and neurogenesis (Saarelainen et al., 2003; Duman and Monteggia, 2006; Leal et al., 2014). BDNF has also been shown to activate the mammalian target of rapamycin (mTOR) signaling pathway (Nosyreva et al., 2013), which is involved in protein synthesis and increased excitatory neurotransmission (Miller et al., 2014).

Studies with NBQX, an $\alpha$-amino-3-hydroxy-5-methyl-4isoxazolepropionic acid receptor (AMPAR) antagonist, and rapamycin, an $\mathrm{mTOR}$ inhibitor, have also shown that the AMPARs and the mTOR signaling pathway are essential for ketamine's antidepressant effects. Li et al. (2010) have shown that ketamine activated growth factor signaling proteins, increased levels of synaptic proteins and AMPAR subunits, and increased dendritic spine densities. These effects were abolished by inhibitors of mTOR, extracellular signal-regulated kinases (ERK) and Protein kinase B (Akt).

Intuitively, all NMDAR non-competitive antagonists might be expected to function in a similar way to ketamine, but that does not hold true for memantine. One explanation is that memantine, unlike ketamine, is a poor blocker of resting NMDAR currents, and that ketamine is a "resting NMDAR blocker", which supports the "direct inhibition" theory of ketamine's antidepressant action (Gideons et al., 2014; Kavalali and Monteggia, 2015). Moreover, memantine neither induced eEF2 de-phosphorylation nor increased BDNF expression (Gideons et al., 2014), and its activity is not affected by mTOR inhibition (Sabino et al., 2013). Another theory for these differential effects of memantine and ketamine is that they could be binding to distinct NMDAR "subpopulations" (Johnson et al., 2015), which might include NMDAR subunit composition and/or synaptic location, though this remains controversial (Wroge et al., 2012; Emnett et al., 2013; Gideons et al., 2014).

\section{NMDAR AGONISTS: MOLECULAR MECHANISMS}

Given the evidence supporting NMDAR antagonists as a new class of antidepressants, it is counter-intuitive that NMDAR agonists are also able to act as antidepressants. In particular, co-agonists of the GluN1 subunit (GLYX13, D-serine) have been shown to improve mood in healthy volunteers, and reduce indices of behavioral despair in rodent behavioral tasks such as the forced-swim test (FST) and the learned helplessness 


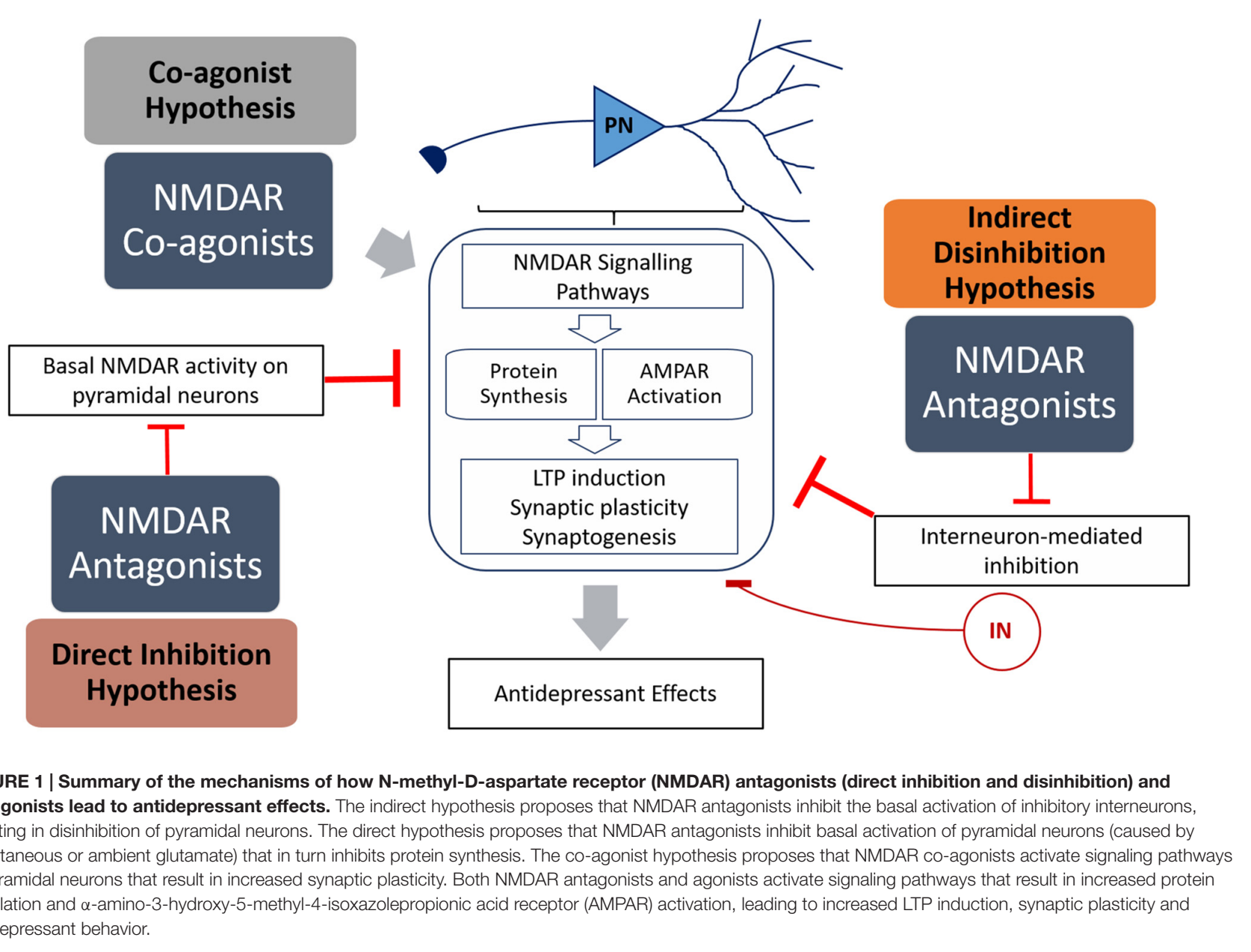

(LH) paradigm (Malkesman et al., 2012; Burgdorf et al., 2013; Levin et al., 2015). In the FST, animals administered with the NMDAR co-agonists exhibited reduced immobility (despondency) in water, which indicated an antidepressant-like effect. In the LH task, the latency to escape a foot-shock is a measure of depressive-like behavior, and NMDAR co-agonists reduced this parameter. Burgdorf et al. (2013) also demonstrated that GLYX13 and ketamine increased surface GluN2B and GluR1 levels in the medial prefrontal cortex (mPFC) and the hippocampus, and increased excitatory post-synaptic current (EPSC) in the hippocampus. This suggested that, in spite of their differential pharmacological properties, common molecular pathways are activated by both compounds.

The glycine transporter inhibitor, sarcosine, has also been shown to attenuate immobility in the FST in mice, and improve mood scores in depressed patients (Huang et al., 2013; Mathew, 2013). An investigation into its psychotropic mechanisms revealed that it induced the phosphorylation of mTOR, ERK and Akt, as well as GluR1 which implies increased membrane insertion of AMPARs (Chen et al., 2015). Parenthetically, although sarcosine is generally recognized as a glycine transporter inhibitor, it also possesses NMDAR co-agonist properties, and can enhance the activation of this receptor through its direct binding to the glycine site on the GluN1 subunit (Zhang et al., 2009a). The antidepressant effects of sarcosine can, therefore, be attributed to the inhibition of synaptic glycine uptake, and/or direct NMDAR stimulation. Nevertheless, overall it appears that mTOR signaling and AMPARs are common downstream targets of both NMDAR agonists and antagonists. This raises the question of how NMDAR modulators that have opposing effects on NMDARs could lead to similar downstream effects. Several theories that have been proposed to explain this phenomenon will now be considered.

\section{PARTIAL AGONISTS AS POTENTIAL ANTAGONISTS: DUAL EFFECTS OF GIUN1 AGONISTS}

Many GluN1 co-agonists are partial agonists that may act as antagonists at higher concentrations, and the most extensively studied of these is D-cycloserine (DCS). It has been proposed that at low concentrations and when the NMDAR glycine site is not fully occupied, DCS acts as an agonist, albeit with a lower efficacy than glycine (van Berckel et al., 1999). At higher concentrations however, DCS can compete with, and 
block, glycine's co-agonist function, thereby reducing activity of NMDARs. This is supported by pre-clinical models and clinical trials for depression and schizophrenia that show the contrasting dose-dependent effects of DCS. While DCS has been shown to improve negative symptoms of schizophrenia in humans at doses below $250 \mathrm{mg}$, doses above that exacerbate the positive symptoms (van Berckel et al., 1999). The reverse is true for depression where doses above $250 \mathrm{mg}$ are necessary to observe antidepressant effects in an add-on clinical trial (Heresco-Levy et al., 2013), suggesting that DCS's antidepressant effects are achieved when it acts as an NMDAR antagonist.

\section{AMPAR CONVERGENCE}

Current literature supports the notion that AMPARs may play an important role in the efficacy of antidepressants. For example, chronic administration of paroxetine and fluoxetine increase the total (Martinez-Turrillas et al., 2002) and phosphorylated levels of GluR1 (Svenningsson et al., 2002, 2007). The importance of AMPAR potentiation has also been demonstrated in studies using positive modulators of AMPARs, such as LY451646 (Andreasen et al., 2015), and in investigations using AMPAR antagonists where the antidepressant properties of fluoxetine and ketamine are blocked (Farley et al., 2010; Li et al., 2010). More recently, Zanos et al. (2016) attributed the antidepressant effects of ketamine to the action of ketamine metabolites on AMPARs.

The activity of AMPAR has also been shown to be important for synaptic potentiation, the mechanism thought to underlie antidepressant actions. While ketamine increased total field potential in the hippocampus, NMDAR-specific field potential decreased, implying that AMPAR and other non-NMDARs contributed to the increase (Nosyreva et al., 2013). This has led to the theory that the key mechanism of action of antidepressants is the increased ratio of AMPAR/NMDAR activity rather than NMDAR antagonism (Andreasen et al., 2013). Therefore, increasing AMPAR activity, decreasing NMDAR activity, or both, would achieve an antidepressant effect. The NMDAR antagonists, such as ketamine, that inhibit NMDAR activity would lead to an increased AMPAR/NMDAR activity ratio. However, drugs that are able to increase AMPAR activity through an NMDAR-independent pathway would also lead to an increased AMPAR/NMDAR activity ratio. For instance, glycine treatment has been shown to increase AMPAR insertion in the synaptic membrane (Lu et al., 2001), which may surpass its NMDAR stimulatory properties. Furthermore, Andreasen et al. have demonstrated that a positive AMPAR modulator and NMDAR antagonist have synergistic antidepressant effects in mice (Andreasen et al., 2013).

\section{NON-NMDAR TARGETS}

When exploring the mechanisms of NMDAR modulators, the assumption made is that the key mode of action of these drugs are NMDAR-dependent. However, this may not be the case. For example, glycine has a high affinity for post-synaptic NMDARs at low concentrations (Zhang et al., 2014), but greater levels in the synaptic cleft could result in spill-over and additional binding to extra-synaptic inhibitory strychnine-sensitive glycine receptors (GlyRs). Thus, elevated synaptic glycine has been associated with increased NMDAR EPSCs and LTP (Johnson and Ascher, 1987), whereas exogenously applied glycine appears to have an inhibitory effect on NMDARs, and subsequent LTD (Chen et al., 2011). Therefore, the same co-agonist could lead to either LTP or LTD, depending on which receptor it preferentially activates (Zhang et al., 2014). Sarcosine may have potentially three modes of action since it is a glycine transport inhibitor (Smith et al., 1992), a NMDAR co-agonist, and has some GlyR agonist properties (Zhang et al., 2009b). Ketamine itself has been shown to bind to and affect non-glutamatergic pathways (Sleigh et al., 2014), such as the opioid system (Gupta et al., 2011). Indeed, it has also been shown that administration of ketamine metabolites result in antidepressant behavior independent of NMDAR inhibition, but dependent on AMPAR activation (Zanos et al., 2016).

\section{"FULL" CO-AGONISTS}

Arguably, the antidepressant action of partial agonists, such as DCS, might be explained by their potential antagonist properties, which is consistent with non-competitive antagonists such as ketamine having the same behavioral effects. However, this does not account for the actions of D-serine, an endogenous co-agonist of the GluN1 subunit that does not act as an antagonist at high doses (Kleckner and Dingledine, 1988; Berger et al., 1998; Mothet et al., 2000). Unlike DCS, sarcosine, and GLYX13, D-serine has a higher affinity than glycine for the NMDAR glycine site and does not bind to other targets (Matsui et al., 1995; Levin et al., 2015). Nevertheless, D-serine has been shown to have antidepressant effects.

An acute dose of D-serine reduced feelings of anxiety and sadness and improved cognitive scores in healthy volunteers (Levin et al., 2015). Likewise, in rodents, an acute dose of D-serine led to improvements in the FST, female urine sniffing test (FUST), and LH paradigm, similar to the antidepressant effects observed after a single dose of ketamine (Malkesman et al., 2012). These actions of D-serine have also been shown to be occluded in GluN1-knock out mice. Reduced immobility in the FST, and reduced latency in the novelty-suppressed feeding test were also observed in mice chronically fed with D-serine, or when the D-serine synthesizing enzyme, serine racemase, was over-expressed (Otte et al., 2013). So how can the antidepressant properties of both $\mathrm{D}$-serine and ketamine be explained? Could preference for particular NMDARsubtypes, their extra-synaptic or synaptic expression, and/or their neuroanatomical location influence the action of receptor modulators?

\section{NMDAR SUBTYPE SPECIFICITY AND LOCALIZATION}

Given that NMDARs are composed of different subunits, some emphasis has been placed on the differential physiological properties of receptors composed of different subunit subtypes, 
A

\begin{tabular}{|cl|}
\hline LEGEND & \\
01 & GluN2A-containing NMDARs \\
- & Glun2B-containing NMDARs \\
0 & D-serine (Co-agonist) \\
- & Glycine (Co-agonist) \\
& Ketamine \\
\hline
\end{tabular}

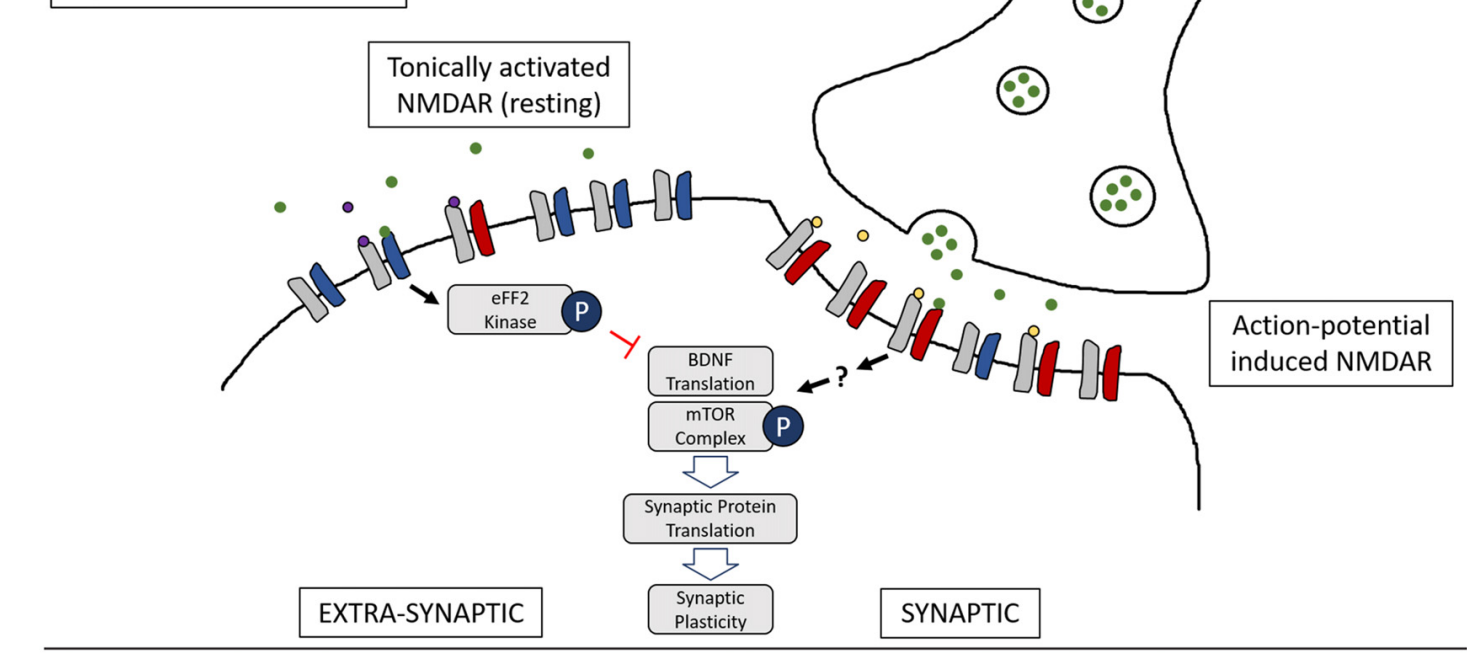

B

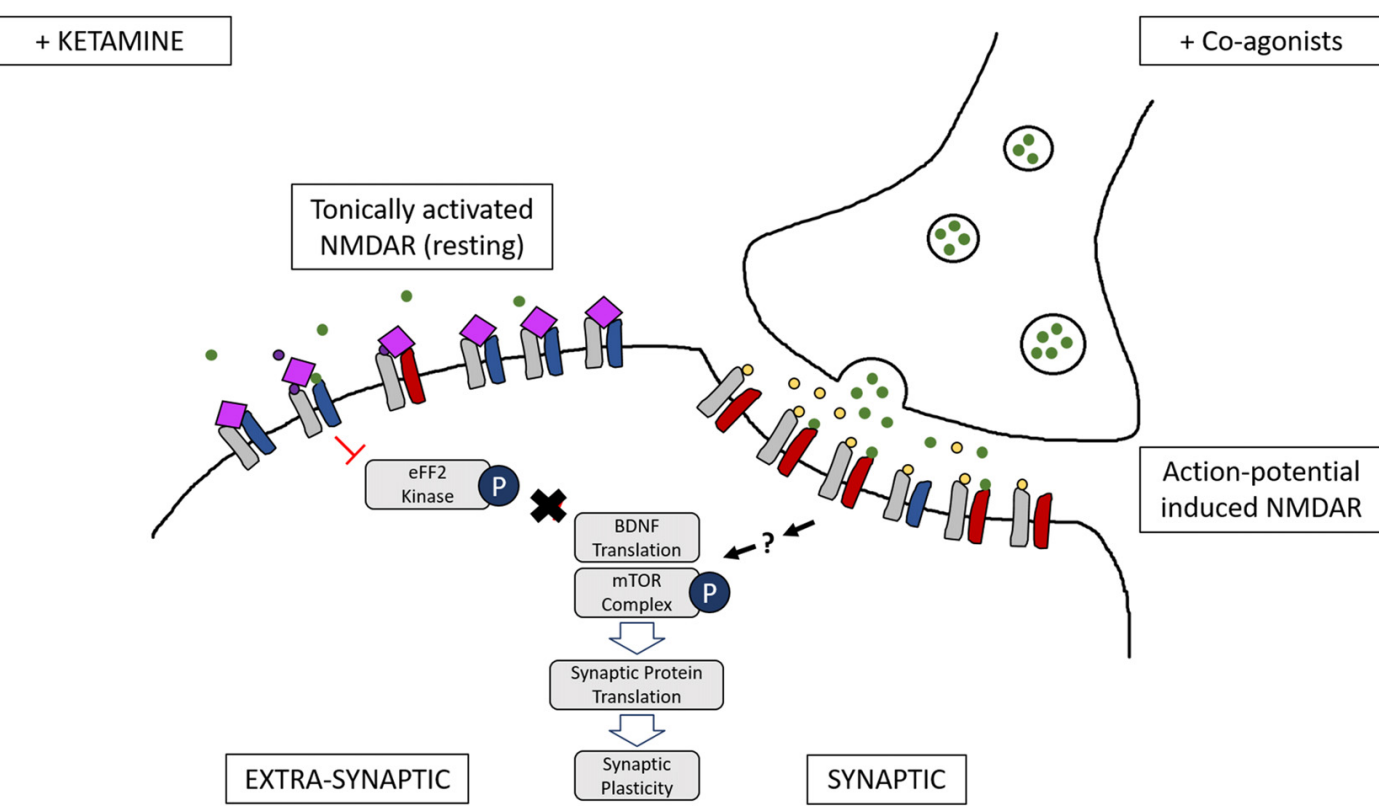

FIGURE 2 | Illustration of a complementary mechanism providing an explanation for how both NMDAR co-agonists and antagonists are able to lead to similar downstream antidepressant effects. (A) Differential activation of NMDARs based on location: tonic activation of extra-synaptic NMDARs by ambient/spontaneous glutamate release lead to inactivation of the mammalian target of rapamycin (mTOR) signaling complex and the inhibition of protein synthesis. On the other hand, action-potential stimulated release of glutamate and the presence of the synaptic co-agonist D-serine leads to activation of synaptic NMDARs, triggering pathways that lead to protein synthesis and synaptic plasticity. (B) Main proposed mechanism underlying complementary antidepressant effects of NMDAR antagonists and agonists: NMDAR antagonists, such as ketamine, inhibit the tonic activation of extra-synaptic NMDARs, resulting in activation of the mTOR signaling complex and protein synthesis. Administration of NMDAR co-agonists, such as D-serine, occupy un-saturated glycine sites on NMDARs, stimulating synaptic NMDARs and leading to LTP and antidepressant effects. Ketamine binding at synaptic sites is not represented. 
in particular GluN2A and GluN2B. Various groups have shown that the GluN2A and GluN2B subtypes are functionally distinct. A popular theory is that GluN2B-containing NMDARs are linked to neurodegeneration, whilst GluN2A-containing NMDARs are linked to neuroprotection (Lujan et al., 2012). Also, different NMDAR subtypes are dominant at different stages of development (Wenzel et al., 1997). For instance, the GluN2B-containing NMDARs play a key role in cortical development, and their loss of function, achieved by knocking out GluN2B, cannot be rescued with other subunits, such as GluN2A (Wang et al., 2011). Furthermore, GluN2B activation has been linked to the suppression of protein synthesis and decreased miniature EPSCs in both developing and adult rodents (Wang et al., 2011; Miller et al., 2014). The subtypes also have different characteristics. The GluN2B subunit, compared to GluN2A, displays higher sensitivity to agonists, and differential sensitivity to the magnesium block (Kuner and Schoepfer, 1996; Erreger et al., 2007; Miller et al., 2014). However, this raises the question of how subtype differences can result in different downstream effects. Several mechanisms have been proposed.

First, the synaptic localization of different subtypes could explain differences in function. That is, GluN2A-containing NMDARs are primarily expressed at synaptic sites, while GluN2B-containing NMDARs are mostly expressed at extrasynaptic sites (Massey et al., 2004). Second, the GluN2 subtypes may convey their specific effects through their structural differences. Experiments have shown GluN2A and GluN2B might regulate different signaling cascades through variances in their intracellular C-terminal tail (Foster et al., 2010). At the ligand binding site, several NMDAR modulators and potential therapeutics have shown a preference for a particular GluN2 subtype (Williams, 1993; Fischer et al., 1997; Paoletti et al., 1997; Nozaki et al., 2011). Interestingly, the GluN2B-containing NMDARs are proposed to underlie the effects of ketamine and GLYX13, because their actions are blocked by GluN2B-specific antagonists, and both compounds increase cell surface levels of GluN2B (Burgdorf et al., 2013). Perhaps more pertinent is the demonstration that the antidepressant fluoxetine binds directly to, and blocks, GluN2B-containing NMDARs (Szasz et al., 2007; Kiss et al., 2012).

Finally, Miller et al. (2014) have shown that GluN2Bcontaining NMDARs are more sensitive to ambient and spontaneous glutamate release, proposing a mechanism where ketamine's direct inhibition of tonic ambient glutamate neurotransmission results in disinhibition of protein synthesis and an overall increase in AMPAR activation and synaptic signaling. Given that Papouin et al. (2012) have demonstrated that synaptic and extra-synaptic NMDARs are gated by different endogenous co-agonists, D-serine and glycine respectively, and that glycine-gated extra-synaptic NMDARs control the ambient glutamate-generated tonic current, it suggests a mechanism where ketamine preferentially inhibits an extrasynaptic pool of NMDARs mainly composed of a GluN2B subunit.

One model, therefore, is that NMDAR agonists preferentially stimulate synaptic NMDARs (action-potential- driven neurotransmission), while NMDAR antagonists block extra-synaptic NMDARs (spontaneous or ambient glutamate-driven neurotransmission; Figure 2). However, research on this has been controversial and a consensus on the exact roles and locations of NMDARs composed of specific subtypes have yet to be elucidated. It has even been suggested that extra-synaptic NMDARs may exist as separate pools with different modes of activation and functions (Papouin and Oliet, 2014).

\section{CONCLUSION}

The modulation of the NMDAR as a potential therapeutic strategy for major depression is supported by compelling evidence, though existing clinical data have not yet eluded to a pathophysiological role of NMDARs in this disorder. That is, both NMDAR antagonists (e.g., ketamine) and agonists (e.g., D-serine) have therapeutic actions in depression, unlike in schizophrenia where the exacerbation of symptoms by ketamine, and their improvement by D-serine, suggests NMDAR hypofunction in psychotic illness. However, molecular considerations do argue the involvement of NMDAR dysfunction in the pathogenesis of depression, particularly with respect to ambient glutamate-driven neurotransmission. Receptor antagonists block this detrimental tonic activation of extra-synaptic NMDARs, while agonists promote synaptic glutamate neurotransmission that leads to synaptic potentiation (Figure 2). In this regard, the therapeutic actions of both receptor antagonists and agonists are accommodated. Of course, further investigations are required to support or refute this hypothesis. Additional patient studies are also required both to substantiate the antidepressant actions of NMDAR modulators, and to show if depressed subjects can be stratified into agonist and/or antagonist responders and non-responders. Nevertheless, molecular studies propose that both NMDAR inhibition and stimulation converge on the activation of BDNF/mTOR signaling. Therefore, it would be interesting to test whether a combination of GluN1 agonist and NMDAR antagonist would have synergistic, reinforcing effects.

\section{AUTHOR CONTRIBUTIONS}

SYC, EM and PWJB made a substantial contribution to the conception, writing and structure of the review article. EM prepared the first draft of the manuscript, and SYC provided subsequent drafts and the final article. PWJB supervised and proof read the manuscript.

\section{FUNDING}

SYC is supported by the National Science Scholarship (NSS) from the Agency of Science, Technology and Research (A*STAR) in Singapore. PWJB currently receives research funding from the Biotechnology, Biological Sciences Research Council, UK (BBSRC, BB/N010035/1). 


\section{REFERENCES}

Andreasen, J. T., Fitzpatrick, C. M., Larsen, M., Skovgaard, L., Nielsen, S. D., Clausen, R. P., et al. (2015). Differential role of AMPA receptors in mouse tests of antidepressant and anxiolytic action. Brain Res. 1601, 117-126. doi: 10.1016/j.brainres.2015.01.001

Andreasen, J. T., Gynther, M., Rygaard, A., Bogelund, T., Nielsen, S. D., Clausen, R. P., et al. (2013). Does increasing the ratio of AMPA-to-NMDA receptor mediated neurotransmission engender antidepressant action? Studies in the mouse forced swim and tail suspension tests. Neurosci. Lett. 546, 6-10. doi: 10.1016/j.neulet.2013.04.045

Autry, A. E., Adachi, M., Nosyreva, E., Na, E. S., Los, M. F., Cheng, P. F., et al. (2011). NMDA receptor blockade at rest triggers rapid behavioural antidepressant responses. Nature 475, 91-95. doi: 10.1038/nature10130

van Berckel, B. N., Evenblij, C. N., van Loon, B. J., Maas, M. F., van der Geld, M. A., Wynne, H. J., et al. (1999). D-cycloserine increases positive symptoms in chronic schizophrenic patients when administered in addition to antipsychotics: a double-blind, parallel, placebo-controlled study. Neuropsychopharmacology 21, 203-210. doi: 10.1016/s0893-133x(99)00014-7

Berger, A. J., Dieudonné, S., and Ascher, P. (1998). Glycine uptake governs glycine site occupancy at NMDA receptors of excitatory synapses. J. Neurophysiol. 80, 3336-3340.

Berman, R. M., Cappiello, A., Anand, A., Oren, D. A., Heninger, G. R., Charney, D. S., et al. (2000). Antidepressant effects of ketamine in depressed patients. Biol. Psychiatry 47, 351-354. doi: 10.1016/s0006-3223(99)00230-9

Burgdorf, J., Zhang, X. L., Nicholson, K. L., Balster, R. L., Leander, J. D., Stanton, P. K., et al. (2013). GLYX-13, a NMDA receptor glycine-site functional partial agonist, induces antidepressant-like effects without ketamine-like side effects. Neuropsychopharmacology 38, 729-742. doi: 10.1038/npp. 2012.246

Burnashev, N., and Szepetowski, P. (2015). NMDA receptor subunit mutations in neurodevelopmental disorders. Curr. Opin. Pharmacol. 20, 73-82. doi: 10.1016/j.coph.2014.11.008

Chen, K. T., Tsai, M. H., Wu, C. H., Jou, M. J., Wei, I. H., and Huang, C. C. (2015). AMPA receptor-mTOR activation is required for the antidepressant-like effects of sarcosine during the forced swim test in rats: insertion of AMPA receptor may play a role. Front. Behav. Neurosci. 9:162. doi: 10.3389/fnbeh.2015.00162

Chen, R. Q., Wang, S. H., Yao, W., Wang, J. J., Ji, F., Yan, J. Z., et al. (2011). Role of glycine receptors in glycine-induced LTD in hippocampal CA1 pyramidal neurons. Neuropsychopharmacology 36, 1948-1958. doi: 10.1038/npp. 2011.86

Downey, D., Dutta, A., McKie, S., Dawson, G. R., Dourish, C. T., Craig, K., et al. (2016). Comparing the actions of lanicemine and ketamine in depression: key role of the anterior cingulate. Eur. Neuropsychopharmacol. 26, 994-1003. doi: 10.1016/j.euroneuro.2016.03.006

Duman, R. S., and Monteggia, L. M. (2006). A neurotrophic model for stressrelated mood disorders. Biol. Psychiatry 59, 1116-1127. doi: 10.1016/j.biopsych. 2006.02.013

Emnett, C. M., Eisenman, L. N., Taylor, A. M., Izumi, Y., Zorumski, C. F., and Mennerick, S. (2013). Indistinguishable synaptic pharmacodynamics of the $\mathrm{N}$-methyl-D-aspartate receptor channel blockers memantine and ketamine. Mol. Pharmacol. 84, 935-947. doi: 10.1124/mol.113.089334

Erreger, K., Geballe, M. T., Kristensen, A., Chen, P. E., Hansen, K. B., Lee, C. J., et al. (2007). Subunit-specific agonist activity at NR2A-, NR2B-, NR2C-, and NR2D-containing N-methyl-D-aspartate glutamate receptors. Mol. Pharmacol. 72, 907-920. doi: 10.1124/mol.107.037333

Farley, S., Apazoglou, K., Witkin, J. M., Giros, B., and Tzavara, E. T. (2010). Antidepressant-like effects of an AMPA receptor potentiator under a chronic mild stress paradigm. Int. J. Neuropsychopharmacol. 13, 1207-1218. doi: $10.1017 /$ S1461145709991076

Fischer, G., Mutel, V., Trube, G., Malherbe, P., Kew, J. N., Mohacsi, E., et al. (1997). Ro 25-6981, a highly potent and selective blocker of N-methyl-D-aspartate receptors containing the NR2B subunit. Characterization in vitro. J. Pharmacol. Exp. Ther. 283, 1285-1292.

Foster, K. A., McLaughlin, N., Edbauer, D., Phillips, M., Bolton, A., ConstantinePaton, M., et al. (2010). Distinct roles of NR2A and NR2B cytoplasmic tails in long-term potentiation. J. Neurosci. 30, 2676-2685. doi: 10.1523/JNEUROSCI. 4022-09.2010
Gideons, E. S., Kavalali, E. T., and Monteggia, L. M. (2014). Mechanisms underlying differential effectiveness of memantine and ketamine in rapid antidepressant responses. Proc. Natl. Acad. Sci. U S A 111, 8649-8654. doi: 10.1073/pnas.1323920111

Gupta, A., Devi, L. A., and Gomes, I. (2011). Potentiation of $\mu$-opioid receptormediated signaling by ketamine. J. Neurochem. 119, 294-302. doi: 10.1111/j. 1471-4159.2011.07361.x

Heresco-Levy, U., Ermilov, M., Lichtenberg, P., Bar, G., and Javitt, D. C. (2004). High-dose glycine added to olanzapine and risperidone for the treatment of schizophrenia. Biol. Psychiatry 55, 165-171. doi: 10.1016/S00063223(03)00707-8

Heresco-Levy, U., Gelfin, G., Bloch, B., Levin, R., Edelman, S., Javitt, D. C., et al. (2013). A randomized add-on trial of high-dose D-cycloserine for treatment-resistant depression. Int. J. Neuropsychopharmacol. 16, 501-506. doi: $10.1017 /$ s1461145712000910

Heresco-Levy, U., Javitt, D. C., Ebstein, R., Vass, A., Lichtenberg, P., Bar, G., et al. (2005). D-serine efficacy as add-on pharmacotherapy to risperidone and olanzapine for treatment-refractory schizophrenia. Biol. Psychiatry 57, 577-585. doi: 10.1016/j.biopsych.2004.12.037

Huang, C. C., Wei, I. H., Huang, C. L., Chen, K. T., Tsai, M. H., Tsai, P., et al. (2013). Inhibition of glycine transporter-I as a novel mechanism for the treatment of depression. Biol. Psychiatry 74, 734-741. doi: 10.1016/j.biopsych. 2013.02.020

Hunt, D. L., and Castillo, P. E. (2012). Synaptic plasticity of NMDA receptors: mechanisms and functional implications. Curr. Opin. Neurobiol. 22, 496-508. doi: 10.1016/j.conb.2012.01.007

Johnson, J. W., and Ascher, P. (1987). Glycine potentiates the NMDA response in cultured mouse brain neurons. Nature 325, 529-531. doi: 10.1038/32 $5529 \mathrm{a} 0$

Johnson, J. W., Glasgow, N. G., and Povysheva, N. V. (2015). Recent insights into the mode of action of memantine and ketamine. Curr. Opin. Pharmacol. 20, 54-63. doi: 10.1016/j.coph.2014.11.006

Kantrowitz, J. T., Malhotra, A. K., Cornblatt, B., Silipo, G., Balla, A., Suckow, R. F., et al. (2010). High dose D-serine in the treatment of schizophrenia. Schizophr. Res. 121, 125-130. doi: 10.1016/j.schres.2010.05.012

Kavalali, E. T., and Monteggia, L. M. (2015). How does ketamine elicit a rapid antidepressant response? Curr. Opin. Pharmacol. 20, 35-39. doi: 10.1016/j. coph.2014.11.005

Kiss, J. P., Szasz, B. K., Fodor, L., Mike, A., Lenkey, N., Kurkó, D., et al (2012). GluN2B-containing NMDA receptors as possible targets for the neuroprotective and antidepressant effects of fluoxetine. Neurochem. Int. 60, 170-176. doi: 10.1016/j.neuint.2011.12.005

Kleckner, N. W., and Dingledine, R. (1988). Requirement for glycine in activation of NMDA-receptors expressed in Xenopus oocytes. Science 241, 835-837. doi: 10.1126/science.2841759

Krystal, J. H., Karper, L. P., Seibyl, J. P., Freeman, G. K., Delaney, R., Bremner, J. D., et al. (1994). Subanesthetic effects of the noncompetitive NMDA antagonist, ketamine, in humans. Psychotomimetic, perceptual, cognitive, and neuroendocrine responses. Arch. Gen. Psychiatry 51, 199-214. doi: 10.1001/archpsyc.1994.03950030035004

Kuner, T., and Schoepfer, R. (1996). Multiple structural elements determine subunit specificity of $\mathrm{Mg}^{2+}$ block in NMDA receptor channels. J. Neurosci. 16, 3549-3558.

Leal, G., Comprido, D., and Duarte, C. B. (2014). BDNF-induced local protein synthesis and synaptic plasticity. Neuropharmacology 76, 639-656. doi: 10 1016/j.neuropharm.2013.04.005

Levin, R., Dor-Abarbanel, A. E., Edelman, S., Durrant, A. R., Hashimoto, K., Javitt, D. C., et al. (2015). Behavioral and cognitive effects of the $\mathrm{N}$-methyl-D-aspartate receptor co-agonist D-serine in healthy humans: initial findings. J. Psychiatr. Res. 61, 188-195. doi: 10.1016/j.jpsychires.2014 12.007

Li, N., Lee, B., Liu, R. J., Banasr, M., Dwyer, J. M., Iwata, M., et al. (2010). mTOR-dependent synapse formation underlies the rapid antidepressant effects of NMDA antagonists. Science 329, 959-964. doi: 10.1126/science.1190287

Lipton, S. A., and Nakanishi, N. (1999). Shakespeare in love-with NMDA receptors? Nat. Med. 5, 270-271. doi: 10.1038/6481

Lu, W. Y., Man, H. Y., Ju, W., Trimble, W. S., MacDonald, J. F., and Wang, Y. T. (2001). Activation of synaptic NMDA receptors induces 
membrane insertion of new AMPA receptors and LTP in cultured hippocampal neurons. Neuron 29, 243-254. doi: 10.1016/s0896-6273(01) 00194-5

Lujan, B., Liu, X., and Wan, Q. (2012). Differential roles of GluN2A- and GluN2Bcontaining NMDA receptors in neuronal survival and death. Int. J. Physiol. Pathophysiol. Pharmacol. 4, 211-218.

Malkesman, O., Austin, D. R., Tragon, T., Wang, G., Rompala, G., Hamidi, A. B., et al. (2012). Acute D-serine treatment produces antidepressant-like effects in rodents. Int. J. Neuropsychopharmacol. 15, 1135-1148. doi: $10.1017 / \mathrm{s} 1461145711001386$

Martinez-Turrillas, R., Frechilla, D., and Del Rio, J. (2002). Chronic antidepressant treatment increases the membrane expression of AMPA receptors in rat hippocampus. Neuropharmacology 43, 1230-1237. doi: 10.1016/s00283908(02)00299-x

Massey, P. V., Johnson, B. E., Moult, P. R., Auberson, Y. P., Brown, M. W., Molnar, E., et al. (2004). Differential roles of NR2A and NR2B-containing NMDA receptors in cortical long-term potentiation and long-term depression. J. Neurosci. 24, 7821-7828. doi: 10.1523/jneurosci.1697-04.2004

Mathew, S. J. (2013). Glycine transporter-I inhibitors: a new class of antidepressant? Biol. Psychiatry 74, 710-711. doi: 10.1016/j.biopsych.2013. 08.019

Matsui, T., Sekiguchi, M., Hashimoto, A., Tomita, U., Nishikawa, T., and Wada, K. (1995). Functional comparison of D-serine and glycine in rodents: the effect on cloned NMDA receptors and the extracellular concentration. J. Neurochem. 65, 454-458. doi: 10.1046/j.1471-4159.1995.65010454.x

Miller, O. H., Moran, J. T., and Hall, B. J. (2016). Two cellular hypotheses explaining the initiation of ketamine's antidepressant actions: Direct inhibition and disinhibition. Neuropharmacology 100, 17-26. doi: 10.1016/j.neuropharm. 2015.07.028

Miller, O. H., Yang, L., Wang, C. C., Hargroder, E. A., Zhang, Y., Delpire, E., et al. (2014). GluN2B-containing NMDA receptors regulate depression-like behavior and are critical for the rapid antidepressant actions of ketamine. Elife 3:e03581. doi: 10.7554/eLife.03581

Morris, R. G., Anderson, E., Lynch, G. S., and Baudry, M. (1986). Selective impairment of learning and blockade of long-term potentiation by an N-methyl-D-aspartate receptor antagonist, AP5. Nature 319, 774-776. doi: 10. 1038/319774a0

Moskal, J. R., Burch, R., Burgdorf, J. S., Kroes, R. A., Stanton, P. K., Disterhoft, J. F., et al. (2014). GLYX-13, an NMDA receptor glycine site functional partial agonist enhances cognition and produces antidepressant effects without the psychotomimetic side effects of NMDA receptor antagonists. Expert Opin Investig. Drugs 23, 243-254. doi: 10.1517/13543784.2014.852536

Mothet, J. P., Parent, A. T., Wolosker, H., Brady, R. O. Jr., Linden, D. J., Ferris, C. D., et al. (2000). D-serine is an endogenous ligand for the glycine site of the N-methyl-D-aspartate receptor. Proc. Natl. Acad. Sci. U S A 97, 4926-4931. doi: 10.1073/pnas.97.9.4926

Nosyreva, E., Szabla, K., Autry, A. E., Ryazanov, A. G., Monteggia, L. M., and Kavalali, E. T. (2013). Acute suppression of spontaneous neurotransmission drives synaptic potentiation. J. Neurosci. 33, 6990-7002. doi: 10 . 1523/JNEUROSCI.4998-12.2013

Nozaki, C., Vergnano, A. M., Filliol, D., Ouagazzal, A. M., Le Goff, A., Carvalho, S., et al. (2011). Zinc alleviates pain through high-affinity binding to the NMDA receptor NR2A subunit. Nat. Neurosci. 14, 1017-1022. doi: 10.1038/ nn. 2844

Olney, J. W., Newcomer, J. W., and Farber, N. B. (1999). NMDA receptor hypofunction model of schizophrenia. J. Psychiatr. Res. 33, 523-533. doi: 10.1016/S0022-3956(99)00029-1

Otte, D. M., Barcena de Arellano, M. L., Bilkei-Gorzo, A., Albayram, O., Imbeault, S., Jeung, H., et al. (2013). Effects of chronic D-serine elevation on animal models of depression and anxiety-related behavior. PLoS One 8:e67131. doi: 10.1371/journal.pone.0067131

Paoletti, P., Ascher, P., and Neyton, J. (1997). High-affinity zinc inhibition of NMDA NR1-NR2A receptors. J. Neurosci. 17, 5711-5725.

Papadia, S., and Hardingham, G. E. (2007). The dichotomy of NMDA receptor signaling. Neuroscientist 13, 572-579. doi: 10.1177/1073858407305833

Papouin, T., Ladépêche, L., Ruel, J., Sacchi, S., Labasque, M., Hanini, M., et al. (2012). Synaptic and extrasynaptic NMDA receptors are gated by different endogenous coagonists. Cell 150, 633-646. doi: 10.1016/j.cell.2012. 06.029
Papouin, T., and Oliet, S. H. (2014). Organization, control and function of extrasynaptic NMDA receptors. Philos. Trans. R. Soc. Lond. B Biol. Sci. 369:20130601. doi: 10.1098/rstb.2013.0601

Reisberg, B., Doody, R., Stöffler, A., Schmitt, F., Ferris, S., and Möbius, H. J. (2003). Memantine in moderate-to-severe Alzheimer's disease. N. Engl. J. Med. 348, 1333-1341. doi: 10.1056/NEJMoa013128

Riedel, G., Platt, B., and Micheau, J. (2003). Glutamate receptor function in learning and memory. Behav. Brain Res. 140, 1-47. doi: 10.1016/s01664328(02)00272-3

Saarelainen, T., Hendolin, P., Lucas, G., Koponen, E., Sairanen, M., MacDonald, E., et al. (2003). Activation of the TrkB neurotrophin receptor is induced by antidepressant drugs and is required for antidepressant-induced behavioral effects. J. Neurosci. 23, 349-357.

Sabino, V., Narayan, A. R., Zeric, T., Steardo, L., and Cottone, P. (2013). mTOR activation is required for the anti-alcohol effect of ketamine, but not memantine, in alcohol-preferring rats. Behav. Brain Res. 247, 9-16. doi: 10.1016/j.bbr.2013.02.030

Sanacora, G., Smith, M. A., Pathak, S., Su, H. L., Boeijinga, P. H., McCarthy, D. J., et al. (2014). Lanicemine: a low-trapping NMDA channel blocker produces sustained antidepressant efficacy with minimal psychotomimetic adverse effects. Mol. Psychiatry 19, 978-985. doi: 10.1038/mp.2013.130

Sleigh, J., Harvey, M., Voss, L., and Denny, B. (2014). Ketamine-more mechanisms of action than just NMDA blockade. Trends Anaesth. Crit. Care 4, 76-81. doi: 10.1016/j.tacc.2014.03.002

Smith, K. E., Borden, L. A., Hartig, P. R., Branchek, T., and Weinshank, R. L. (1992). Cloning and expression of a glycine transporter reveal colocalization with NMDA receptors. Neuron 8, 927-935. doi: 10.1016/0896-6273(92) 90207-t

Svenningsson, P., Bateup, H., Qi, H., Takamiya, K., Huganir, R. L., Spedding, M., et al. (2007). Involvement of AMPA receptor phosphorylation in antidepressant actions with special reference to tianeptine. Eur. J. Neurosci. 26, 3509-3517. doi: 10.1111/j.1460-9568.2007.05952.x

Svenningsson, P., Tzavara, E. T., Witkin, J. M., Fienberg, A. A., Nomikos, G. G., and Greengard, P. (2002). Involvement of striatal and extrastriatal DARPP-32 in biochemical and behavioral effects of fluoxetine (Prozac). Proc. Natl. Acad. Sci. U S A 99, 3182-3187. doi: 10.1073/pnas.052712799

Szasz, B. K., Mike, A., Karoly, R., Gerevich, Z., Illes, P., Vizi, E. S., et al. (2007). Direct inhibitory effect of fluoxetine on N-methyl-D-aspartate receptors in the central nervous system. Biol. Psychiatry 62, 1303-1309. doi: 10.1016/j.biopsych. 2007.04.014

Tsai, G., Lane, H. Y., Yang, P., Chong, M. Y., and Lange, N. (2004). Glycine transporter I inhibitor, N-methylglycine (sarcosine), added to antipsychotics for the treatment of schizophrenia. Biol. Psychiatry 55, 452-456. doi: 10.1016/j. biopsych.2003.09.012

Tsai, G. E., Yang, P., Chang, Y. C., and Chong, M. Y. (2006). D-alanine added to antipsychotics for the treatment of schizophrenia. Biol. Psychiatry 59, 230-234. doi: 10.1016/j.biopsych.2005.06.032

Wang, C. C., Held, R. G., Chang, S. C., Yang, L., Delpire, E., Ghosh, A., et al. (2011). A critical role for GluN2B-containing NMDA receptors in cortical development and function. Neuron 72, 789-805. doi: 10.1016/j.neuron.2011. 09.023

Wenzel, A., Fritschy, J. M., Mohler, H., and Benke, D. (1997). NMDA receptor heterogeneity during postnatal development of the rat brain: differential expression of the NR2A, NR2B and NR2C subunit proteins. J. Neurochem. 68, 469-478. doi: 10.1046/j.1471-4159.1997.68020469.x

Williams, K. (1993). Ifenprodil discriminates subtypes of the N-methyl-Daspartate receptor: selectivity and mechanisms at recombinant heteromeric receptors. Mol. Pharmacol. 44, 851-859.

Wroge, C. M., Hogins, J., Eisenman, L., and Mennerick, S. (2012). Synaptic NMDA receptors mediate hypoxic excitotoxic death. J. Neurosci. 32, 6732-6742. doi: 10. 1523/JNEUROSCI.6371-11.2012

Zanos, P., Moaddel, R., Morris, P. J., Georgiou, P., Fischell, J., Elmer, G. I., et al. (2016). NMDAR inhibition-independent antidepressant actions of ketamine metabolites. Nature 533, 481-486. doi: 10.1038/nature 17998

Zarate, C. A. Jr., Singh, J. B., Quiroz, J. A., De Jesus, G., Denicoff, K. K., Luckenbaugh, D. A., et al. (2006). A double-blind, placebo-controlled study of memantine in the treatment of major depression. Am. J. Psychiatry 163, 153-155. doi: 10.1176/appi.ajp.163.1.153 
Zhang, H. X., Hyrc, K., and Thio, L. L. (2009a). The glycine transport inhibitor sarcosine is an NMDA receptor co-agonist that differs from glycine. J. Physiol. 587, 3207-3220. doi: 10.1113/jphysiol.2009.168757

Zhang, H. X., Lyons-Warren, A., and Thio, L. L. (2009b). The glycine transport inhibitor sarcosine is an inhibitory glycine receptor agonist. Neuropharmacology 57, 551-555. doi: 10.1016/j.neuropharm.2009.07.019

Zhang, X. Y., Ji, F., Wang, N., Chen, L. L., Tian, T., and Lu, W. (2014). Glycine induces bidirectional modifications in N-methyl-D-aspartate receptormediated synaptic responses in hippocampal CA1 neurons. J. Biol. Chem. 289, 31200-31211. doi: 10.1074/jbc.M114.570630

Zhou, X., Ding, Q., Chen, Z., Yun, H., and Wang, H. (2013). Involvement of the GluN2A and GluN2B subunits in synaptic and extrasynaptic N-methylD-aspartate receptor function and neuronal excitotoxicity. J. Biol. Chem. 288, 24151-24159. doi: 10.1074/jbc.M113.482000
Zorumski, C. F., Nagele, P., Mennerick, S., and Conway, C. R. (2015). Treatmentresistant major depression: rationale for NMDA receptors as targets and nitrous oxide as therapy. Front. Psychiatry 6:172. doi: 10.3389/fpsyt.2015.00172

Conflict of Interest Statement: The authors declare that the research was conducted in the absence of any commercial or financial relationships that could be construed as a potential conflict of interest.

Copyright (c) 2017 Chan, Matthews and Burnet. This is an open-access article distributed under the terms of the Creative Commons Attribution License (CC BY). The use, distribution and reproduction in other forums is permitted, provided the original author(s) or licensor are credited and that the original publication in this journal is cited, in accordance with accepted academic practice. No use, distribution or reproduction is permitted which does not comply with these terms. 